\begin{tabular}{|c|c|c|c|}
\hline $\begin{array}{l}\text { IVERSITETASA } \\
\text { I. }\end{array}$ & $\begin{array}{l}\text { Escola Superior } \\
\text { de Cestâo e } \\
\text { Tecnologia } \\
\text { [iPSantarém] }\end{array}$ & 檞 & $\begin{array}{l}\text { ISSN 2029-7564 (online) } \\
\text { SOCIALINĖS TECHNOLOGIJOS } \\
\text { SOCIAL TECHNOLOGIES } \\
2014,4(1) \text { p. } 51-61\end{array}$ \\
\hline
\end{tabular}

\title{
ONLINE RADICALISATION: THE NET OR THE NETIZEN?*
}

\author{
Femi Richard Omotoyinbo \\ Independent researchers* ${ }^{* *}$ Nigeria, Jesusphilosopher@live.com \\ doi:10.13165/ST-14-4-1-04
}

\section{Abstract}

Purpose. Radicalisation has gained some unusual prominence in the academic circles; maintaining a generic existence not only in the political sector. And with the advent of the Information Communication Technology (ICT), radicalisation has begun to have some virtual dimension even in the remotest of human communities. This study seeks to mobilise a universal awareness on the collective urgency to oppose Online Radicalisation (a radicalisation that happens through the internet) due to its propensity to engendering conflicts. It also aims at identifying the principal cause of online radicalisation and steer a clear course for a practical reversal in the systems of online radicalisation.

Design/methodology/approach. The study is divided into three primary parts. The general notion of radicalisation is the focus of the first part; which is further analysed into the levels of online radicalisation with its accompanying developments and segments. The second part utilises analytic and historical method to pinpoint the principal cause of online radicalisation amidst the suspected causal factors (the Net and the Netizen). The final part analytically focuses on the Netizen (a user/citizen of the internet) as the primary cause of online radicalisation and how the global community can bring about a corresponding change in the Net by the application of some measures on the Netizen.

The Author appreciates Professor Scott Decker, the Foundation Professor and Director School of Criminology and Criminal Justice, Arizona State University, USA, for his crucial comments and corrections provided at the early phase of this work. Sincere gratitude also goes to the two unknown Reviewers for their insightful suggestions.

* Alumna of the Philosophy Department, Adekunle Ajasin University Akungba-Akoko, Ondo State, Nigeria. 
Findings. By virtue of the analytic plus historical methods employed by this study; it has been initially identified that radicalisation is basically having two versions which are online and offline. Further emphasis on the online version reveals that its existence is only made possible by the availability of the internet (the Net). Since the Net is a global phenomenon, online radicalisation is considered to be worldwide: a menace of globalisation. However, the study later indicated that the Net is a facilitator and not a cause of online radicalisation. A view was deduced that the Netizen is of two categories that include the broad category and the jargon category. The Netizen in the former category was later on conceived as the principal cause of online radicalisation.

Research limitations/implications. The study averred that all attempts/measures to bring about a reversal in the status quo of online radicalisation [de-radicalisation measures] should be directly applied to the principal cause, which is the Netizen. Although the content of the de-radicalisation measures were not fully provided by this study due to the reason that the contents can best be supplied by almost everyone that has a vivid understanding of online radicalisation. The study continues to affirm that the application of the measures of de-radicalisation on the Netizen will bring a corresponding ameliorative effect on the Net against its perpetuation of online radicalisation.

Practical implications. It is important for domain name providers, governments, internet serviceproviders, mass media, NGOs, parents, politicians, religious organisations, schools, teachers, and web hosting companies to collaborate to create practicable contents for a Gradual Online De-Radicalisation (G.O.D) which will suppress the perturbing rate of Online Radicalisation to the minimal. No unit or sector can singly tackle online radicalisation effectively. Therefore, measures of de-radicalisation should be governed by international treaties and laws, and there should be credible agents to legislate and execute the laws respectively.

Originality and value. This study broadens the possibilities of reducing online radicalisation to the barest minimum globally with some novel strategies categorised broadly as Gradual Online De-Radicalisation (G.O.D). The analytic methods applied were plausible skills from the realm of Philosophy and Science respectively. Thus, the findings and suggestions of this study are considered reasonable and universally pragmatic.

Keywords: social technologies, online radicalisation, social media, gradual online de-radicalisation (G.O.D), the Net, the Netizen.

Research type: general review and viewpoint

\section{Introduction}

Language is a phenomenon that keeps stretching without a possible prediction of its reaching any elastic limit. The glossary of labels usually accommodates letters and words that frequently develop as semantic representations of events as they occur in the universe. Such words and letters did not only exist to complement the verbosity of think-tanks; they are crucial emblems of perturbing circumstances that 
affect individuals globally. Obviously, it is a combination of two words "Online" and "Radicalisation" that formed the term Online Radicalisation. So to start this work on a good note; online radicalisation will be initially collapsed and distinctly explained before examining the duo collectively.

More often than not, radicalisation has always been viewed from political perspectives. For example, it was construed as a process leading towards the increased use of political violence. In a similar vein, radicalisation is also conceptualised as a process characterised by increasing commitment to and use of violent means and strategies in political conflicts (McCauley and Moskalenko, 2008).

This work will not fully concur that these political perspectives give a clear idea of what radicalisation really means. The reason for this is that the radicalisation to be discussed is not limited to the confines of politics; it is rather a radicalisation in its wholeness.

A definition with some relevance is that radicalisation is the process of developing extremist ideologies and beliefs (Brown, 2011). In this way, radicalisation is not in the restricted sense because the extremist ideologies and beliefs may fall into any sphere of existence; be it political, religious or racial. Generally, radicalisation may be acceptable in the elaborative view of Angus Smith as the process by which individuals are introduced to an overtly ideological message and belief system that encourages movement from moderate, mainstream beliefs toward extreme views (Angus, 2013). All the same, radicalisation remains a process all through. In this paper, radicalisation will simply be taken as any peculiar process devised by some individuals or groups to proclaim and defend some subjective ideologies and beliefs which might be objectively detrimental in the long run. The peculiarity of radicalisation is intriguingly contained in its propensity to conflicts. Though it may be the case that not all radicalisation breeds conflict; but fear is inlaid in its extreme procedures to destabilising public security. It is now the case that the Net fosters the spread of radicalisation with its accompanying violence.

The other concept in this work is the word "Online", which has gained principal attention in contemporaneous milieu. Although this concept has been engaged in much informal interpretations; it is for the purpose of this work that its formal descriptions will be reiterated. "Online" refers to being connected to the internet or any remote service where there is no delay in accessing the network. The information desired is thereby available for immediate usage. The fecundity of this concept has lured into existence some similar words. Some of these words include: "cyberethics," "cyberspace", "net", "netiquette", "Netizen", etc. However, the "net" is a short derivation of the Internet (International Network) which is comprehensively seen as:

A subset of cyberspace ... a system of interconnected computer networks. [That] is comprised of both hardware and software that facilitate data transfer across a network of networks, ranging from local to global in scale, and encompassing private, public, corporate, government and academic networks. Functioning primarily as a global data exchange system, it carries a wide range of resources such as email, instant messaging, file transfer, virtual worlds, peerto-peer file sharing, and the World Wide Web

(Stevens and Neumann, 2009). 
Netizen [also known as Nettie], in its broad usage, refers to individuals that use the Net (Internet) for whatever purpose. As a jargon, it is about the professional structuring and utilisation of the Net towards meritorious motives. Collectively, Netizen connotes a citizen of the internet (Hauben and Hauben, 1997).

\section{The Notion of Online Radicalisation}

One can by means of the above fathom the definition of online radicalisation; by making a conjunction of the prior segmented explanation of the concepts. In this wise, online radicalisation is thus a radicalisation that happens through the internet: a peculiarly modern process of developing extremist ideologies and beliefs so as to make them publicly available and emotively accessible to the populace through the processes of the internet.

The polarity of existence makes it indubitable to affirm an existence of a variant type which is identified here as Offline Radicalisation. It is simply a radicalisation that does occur without the intervention of the internet. The offline radicalisation is certainly older than online radicalisation because the offline world (non-virtual world) has always been available sooner than the development of the online counterpart. This work seeks to formally add to the existing knowledge that radicalisation, in this age of Information Communications Technology (ICT), is basically of two ramifications i.e. Offline and Online.

In all its ramifications, radicalisation has been observed to have three main operational levels which are Macro, Meso and Micro. These are respectively about its appearances in socio-political environments, armed groups and individual experiences (Della Porta and Lafree, 2012). Radicalisation is thus a phenomenon that has gone deep into all the fabrics of human reality. With the advent of the internet, radicalisation (the online type) began to gain access to a liberal outlet (Net) and thereby directly or indirectly intervened in almost the totality of the global community.

Nowadays, home-grown terrorism, spread of propaganda messages and recruitments into radical sects are perfectly actualised by the use of the Net (Thompson, 2011). Via the Net, radicalisation sufficiently covers its three operational levels: there are socio-political ideologists using the social media and websites to advocate for support [Macro level]. There are armed groups, terrorists and gangs trying to establish a global clique on the internet [Meso level] and there are youthful individuals with passions of finding daily friends online; learning new things and showing solidarity to their celebrated sects [Micro level].

It is little wonder to notice the interconnectedness of radical sects (either surreptitious or audacious ones) all over the seven continents of the world (United States Central Intelligence Agency, 2003). With the similarities in the strategies, it easily shows that world terrorism today is likened to branches from the same stem. By virtue of the internet, the audacious radical groups can stimulate the creation of some local ones in geographically distant corners of the world. It is naturally believed that there is more "convergence across criminal and extremist groups than divergence." 
(Decker and Pyrooz, 2011). But in this era of the internet; there is much to be imagined. The internet plays a central role in the evolution of gangs and radicalisation because of the ability to broadcast key symbols, images and rhetoric worldwide in a matter of minutes (Decker and Pyrooz, 2011). The culmination of the meso level and the micro level has even reached a perturbing peak with the usage of the Net by terrific radicals. There is the persistent issue of recruitment and passing of propaganda messages on the internet and everyone seems to be susceptible.

Many of the radical groups occupying the meso level do pass out frequent messages in the form of e-newsletters to their loyalists and every interested individual at the micro level. A recent visit to the Al-Qaeda's website reveals that the radical group has enabled itself to recruiting and accommodating interested individuals from almost 250 countries of the world.

Information from the Washington Times seems to affirm that radical groups do compete (probably for membership) online by hacking and distorting the rivals online interfaces. Despite the rival attacks and the close watch of the United States intelligence agencies; most of the victimised radicals do find a pleasant solace in the usage of electronic mails and Twitter (Gertz, 2013).

It is frequently opined that the lineaments inherent in the Net have made it to permit a free flow of radicalisation. The Net, in the format of social media, online community and similar networks, has much aided radicalisation into becoming a global phenomenon.

The Net (internet) is widely available and everyone is easily connected to rally support for a cause or ideology. In the social media format, the Net is an effective tool to radicalise and recruit members into a cause. It is ever available for the users beguiling them with the hope of rewards and satisfaction than seen offline.

Moreover, activities on the Net are usually not in the auspices or surveillance of anyone. Youths with connected mobile device can lurk in the corners of online communities in order to compensate for their lack of stoic solidarity elsewhere. Online community is said to have emerged as a palliative to civic erosion, [it] exists to address specific problem, either the lack of other spaces for political action or lack of affective spaces within offline communities (Cavanagh, 2007). The Net as a cyberspace is a safe haven for the users [Netizens] who may desire to be discreet about their personal identities. Without any mask, a Netizen can stroll on the streets of the cyberspace, explosives in hands, without any fear of a patrolling cop. The Net is a sound for every voice. People who have no relevance in the offline communities can gain one online and ease their burden. There is no such thing as over-crowdedness on the Net. With the existence of multi-user domains (MuDs) the Net is infinitely admissive; every living soul can acquire a personal breathing space therein (Soeters, 2005). One will not be taken aback in any manner to notice allegedly dissimilar entities cohabiting under the same roof on the Net (i.e. @alqaeda and @Barack Obama on Twitter). It simply shows that none can extensively limit the presence of another (who might be an enemy) on the Net.

These lineaments, among others, have almost made one to believe that radicalisation signifies the teleological usage of the Net. 


\section{The Cause of Online Radicalisation}

To this extent, this work will assume that there are two collaborative causes of online radicalisation. On one hand, there is the Net and on the other hand, there is the Netizen. From an ethical perspective; it may not be so easy to identify the primary culprit culpable for the existence of online radicalisation between the Net and the Netizen. For the purpose of this study, there will be an attempt to create some substantial grounds by which either of the two will be ethically apprehended as the primary cause of online radicalisation. We will start this activity with the Net.

Numerous grounds exist to incriminate the Net as the evil genius that mostly promotes online radicalisation rather than the Netizen. It can be recalled from the previous part of this work that the lineaments of the Net suitably allow the existence of online radicalisation. This permissive nature of the Net is sound enough to allow the allocation of blames to the Net as pertaining online radicalisation.

Apart from this argument, the structure of the Net has also made all borders to be susceptible to the intrusion of online radicalisation. As unravelled by an Investigation Programme: the new look of websites, contents, chat rooms and forums, the online games, audio-visuals and multimedia messaging have all been poised towards the perpetuation of online radicalisation (Royal Canadian Mounted Police, 2011). The Net in its forms and appearances has fully aided online radicalisation and thus cannot be acquitted from being referred to as the evil-genius behind online radicalisation.

Moreover, online radicalisation could not have existed if the Net had remained outside existence. In fact, there would have been nothing like the Netizen too. It seems directly apparent that the Net is morally culpable for the existence of online radicalisation because the Netizen has no conceptual existence if not pre-determined by the Net. Instead of trying to blame the Netizen for online radicalisation; it is effortlessly reasonable to accuse the Net as the primary cause or the main culprit.

In order to stay clear of dogmatic claim or hasty generalisation, this work will now take further verification to evidently nail the Net as the culprit. This conclusive verification will peer into the consciousness and conscience of the Net as well as its essence and existence. Although this work seems to have personified the Net; it will continue in the same manner by subsuming consciousness and conscience into the concept of Mind.

Before presenting the Net as the main cause of online radicalisation it is important to verify if at all, the Net has a conscience and a consciousness of what it does. If the Net is conscious of its perpetuation of online radicalisation; what main effect does the consciousness have on its conscience? This bifocal inquiry is basically about the mindedness of the Net.

Without excessive analysis, this inquiry on the mindedness of the Net will be guided through what is known as Intentional Realism. Intentional realism is the philosophical view that there are genuine intentional states (Graham, 1993). It is believed (under intentional realism) that things have intentionality; meaning that they are directed towards something. A phenomenon can be regarded as having mind 
if such direction towards something (Intentionality) is not only in the view of the observer but does truly inhere in the subject observed (Graham, 1993).

As a corollary to this, the Net can only be regarded as having mind if its intentionality towards online radicalisation is really comprehended by itself and not only comprehended by its analysts, users and security personnel. And this is never so. This inquiry tends to strip the Net of its human appearance, thereby making it probable that the Net has no conscience, consciousness or mind to mind its perpetuation of radicalisation. If the Net is bereft of a Mind, it will be most futile to seek its possibility of having consciousness or conscience. Therefore, the assumption that the Net is a cause of online radicalisation is untenable and baseless.

The mindedness of the Net is also evidently denied in some socio-scientific investigation taken by Nass and Moon (2000) that the human feelings attributed to [the Net or] computers by people are due to circumstances like emotional attachment to computers, politeness and intimacy among others. And people [Netizens] are lured into making reactions regarded as Ethopoeia towards the Net. It is, therefore, incoherent to take the Net as human, conscious or having conscience. With these arguments, the chances of nailing the Net as morally culpable for online radicalisation now become very limited.

A historical allusion reveals that "[the Net] was the result of some visionary thinking by people, in the early 1960s; that saw great potential value in allowing computers to share information on research and development in scientific and military fields" (Howe, 2012).

This allusion aptly reveals a lot about the existence and essence of the Net. Firstly, it is revealed that the essence of the Net comes before its existence. The Net has sharing of information on research and development in scientific and military fields as its essence (responsibility) even before its availability. The existence (availability) of the Net was thus to satisfy that responsibility. However, the Net was not formed by itself: its existence was a result of human thoughts and activities.

The relevance of the above findings is that the Net is increasingly a human development; purposely formed to satisfy some scientific and military yearnings which are devoid of radicalisation.

It is therefore far from the truth that the Net is a tool of radicalisation and humanity is only utilising it according to its nature. Although the existence of the Net reformed human beings into becoming Netizen(s), but it was human beings that formed the Net and enabled its existence to reform them.

In view of the above analysis of the Net from the realm of existence and essence; it is no more fallacious to vindicate the Net from being highlighted as the primary cause of online radicalisation.

John Stuart Mill's Method of Residue $e^{1}$ might permit us to claim that the Netizen is the primary cause of online radicalisation because it is the leftover.

1 Method of Residue consists of separating from a group of causally connected conditions and phenomena those strands of causal connections that are already known, leaving the required causal connection as the residue [See Patrick J. Hurley, A Concise Introduction to Logic, (Belmont: Wadsworth, 2000), 513]. 
However, for the sake of clarity, there will be a quick appraisal of available facts to buttress such plausibility. First, one can argue from the preceding findings that human beings formed the Net and can, therefore, actively manoeuvre it to satisfy any purpose including radicalisation. Human beings (as the Netizens) are the determinants of the contents of the Net and such contents may be extended beyond the scope of science and the military. The Net lacks all ability to remonstrate and prevent any benignant or malignant utilisation. The Net is not human and it is more of a passive tool that can be activated for diverse purposes, notwithstanding the current existence of ALICE (Artificial Linguistic Internet Computer Entity). The Net is to the Netizen what the clay is to the potter: the Netizen is probably the consciousness or conscience of the Net.

It is true that human beings made the Net; and that the motive was priorly a good one; but the dynamic nature of humanity led to the widening of the horizons of the Net so that it became an available tool for radicalisation. Credence can be derived from Walt Howe (2012) that "as the [Net] became ubiquitous, faster, and increasingly accessible to non-technical communities, social networking and collaborative services have grown rapidly, enabling people to communicate and share interests in many more ways."

To adhere strictly to this view, one will be compelled to diversify the notion of the Netizen once more and adjudged anyone on the broad category of the word as the main culprit behind the perpetuation of online radicalisation. The reason for this position is that early Netizens (in the jargon form) created the Net with good intentions i.e. to aid access to communications in scientific and military fields. It was for this early period that the comment of the US President Bill Clinton seemed relevant that with the existence of the Net people could "do more public good than ever before." (Harvard University Gazette, 2007). The early Netizens may not be culpable for inimical results arising from the later usage of the Net.

The Net (in its later appearance) is thus a necessary factor of online radicalisation, while the Netizen (in its broad form) is a sufficient and primary cause of online radicalisation.

All these evaluations are not to show that the Netizen is the criminal and that the Net is a saint; they are, rather, to show that the Netizen is the criminal and that the Net is a guiltless accomplice.

\section{Online De-Radicalisation and its Plausibility}

Evaluations carried out above are to underpin the opinion of this paper that in all ameliorative steps taken or to be taken towards online radicalisation; the two concepts (i.e. the Net and the Netizen) should be targeted with keen emphases on the Netizen the primary cause.

To be clear, this work intimates that any attempt of online de-radicalisation will be very successful if it places more focus on the Netizen.

De-radicalisation is semantically a reversal in radicalisation (Della Porta and Lafree, 2012). It is usually a systematic regress in radicalisation process to counteract the existing effects and the furtherance of radicalisation in its operational levels. 
The worst ways of attempting online de-radicalisation include excessive focus on the Net (websites and materials) and segregated implementation of de-radicalisation measures.

The Net is indeed a crucial factor to be considered in online de-radicalisation. It is therefore good for analysts, intelligence departments and global decision-makers, in the confines of national security, to be actively engaged in the activities of the Net. It is also a valuable motive to filter out inappropriate contents and provide alternative sites and contents for the Netizens.

Nevertheless, ameliorative measures should not only focus on the Net as shown above and minus the users of the Net. Online de-radicalisation should not only be about cyber-purging; it should involve the inculcation of some cyber-ethics to be followed by the Netizen(s). This correlates with the view that "monitoring and the disruption of internet sites by law enforcement agencies is only a temporary measure as the material is often duplicated elsewhere with the click of a mouse." (Royal Canadian Mounted Police, 2011). The global community should thus be ordered to acknowledge online radicalisation as a global crime against humanity which is guided by strict penalties. This will be more feasible than attacking the Net itself.

It is important to note that the above measures may be futile if they are not internationally complemented with treaties or laws and some credible agents to legislate and execute the laws respectively. Every Netizen should be aware of the responsibilities that go with surfing the Net.

Moreover, the measures of online de-radicalisation should not be implemented in a segregated manner. That is to say, the measures should be implemented via collaborative efforts of domain name providers, governments, internet service providers, mass media [involving the entertainment industries, e.g. the Bollywood, the Hollywood, the Nollywood etc], NGOs, parents, politicians, religious organisations, schools, teachers, and web hosting companies. No unit or sector can singly tackle online radicalisation effectively. For all measures of online de-radicalisation to be successful, they must be implemented or utilised to cover the three operational levels of radicalisation (i.e. the macro, meso and micro levels): all hands must be on deck for such to be a reality. Online de-radicalisation should be taken seriously as a big battle against online predators. That is why online radicalisation should also be part of computer literacy syllabi in all cadres of learning. Ministries of information, web developers/programmers and internet service providers should devise means of identifying any signal of online radicalisation and should encourage reportage of radical materials found online. There should be compulsory ads emphasising and prohibiting online radicalisation on websites plus wapsites.

Online radicalisation is said to have a major employment of youths: it therefore demands caution in attempting de-radicalisation (Whitney, 2009). A cataclysmic change may not be the outcome of the de-radicalisation processes. Online deradicalisation should not be appraised as a radical surgery that will bring everything to normalcy in a matter of minutes. Online radicalisation has its history and its trends; before everything about online radicalisation can be wiped out, history must be created and some trends will be followed too. This paper will briefly posit here 
that online radicalisation can be halted or minimised by a method conceived by this work as Gradual Online De-Radicalisation (G.O.D). This method will not only be a summation of dynamic measures (including those previously discussed); but it is also about the gradual and consistent application of the measures to the Netizen with a corresponding effect on the Net, so to disengage both from radical practices and appearances.

Although elaborate contents of these measures are reserved for future discussions and developments; yet these measures should be dynamic so as not to be overridden by constant usage or cheaply fended off by online predators. Gradual Online DeRadicalisation (G.O.D) must be a consistently collective movement painstakingly taken to reverse the status quo.

\section{Conclusion}

In a nutshell, online radicalisation should not be taken with uncertainty or tackled without concerted plans. Radicalisation (in its online form) has infiltrated not only the western world, but the entire world (Thompson, 2011). At this contemporaneous level of ICT one cannot imagine the rate at which radicalisation could permeate all borders of human existence. And it is unfortunate that its evils are majorly felt offline. Online radicalisation is evidently a menace of globalisation: the Net is accessible from all corners of the globe; there should be no country or state that should be recalcitrant or see itself as inoculated against the menace. Developing countries should begin to understand that they do not only have the land and sea borders to protect. They should guard the online boarders too and measures should be devised to maintain their virtual sovereignty. There should be diplomatic steps to manage the Net and the Netizen against the continuation of radicalisation. Although the Net has no mind, the Netizen remains its consciousness. The Netizen thus has freedom to make choices for its developments. To properly manoeuvre the Net away from its perpetuation of radicalisation, efforts must firstly be directed to the Netizen being the primary cause of online radicalisation.

This work also sees this step as a springboard for any successful amelioration of radicalisation: which is presently very urgent. The possibility of online peace [on the Net] has a corresponding effect on the offline realm. The offline and the online spheres are so causally linked that one will always see the situation as apposite with the Yahoo axiom that: "...you get more out of the web, you get more out of life!"

\section{Bibliography}

Angus, S. 2009. Radicalization - A Guide for the Perplexed [interactive]. [accessed 201309-23] <http://www.rcmp-grc.gc.ca/pubs/ nsci-ecrsn/radical-eng.htm>.
Brown, R. 2011. Radicalization and Involvement in Violent Extremism I: a Review of Definitions and Applications of Social Science Theories. Journal of Strategic Security., 4(4): Winter. 
Cavanagh, A. 2007. Sociology in the Age of the Internet. New York: McGraw Hill/OUP.

Central Intelligence Agency. 2003. National Strategy for Combating Terrorism. CIA: United States.

Decker, S. and Pyrooz, D. 2011. Gangs, Terrorism and Radicalization. Journal of Strategic Security 4 (4): 151-166.

Della Porta, D. and Lafree, L. 2012. Processes of Radicalization. International Journal of Conflict and Violence., 6 (1): 5-10.

Gertz, B. 2013. Inside the Ring, The Washington Times, May, 15.

Graham, G. 1993. Philosophy of Mind. Oxford: Blackwell.

Harvard University Gazette. 6 June 2007. Remarks of former U.S. President Bill Clinton. [interactive]. [accessed 2010901-28] <http://www.news.harvard.edu/ gazette/2007/06.07/99-clinton.html>.

Hauben, M. and Hauben, R. 1997. Netizen: An Anthology. IEE Computer Society Press.

Howe, W. A Brief History of the Internet [interactive]. [accessed 2012-09-13] <http:// walthowe.com/navnet/history.html $>$.

McCauley, C. and Moskalenko, S. 2008. Mechanisms of Political Radicalization:
Pathways toward Terrorism. Terrorism and Political Violence., 20: 415-433.

Nass, C. and Moon, Y. 2000. Machines and Mindlessness: Social Responses to Computers. Journal of Social Issues. 56 (1): 81-103.

Royal Canadian Mounted Police (RCMP. GCR). 2011. Youth Online and at Risk: Radicalization Facilitated by the Internet. National Security Investigation Program. [interactive]. [accessed 2013-08-29] <http:// rcmp-grc.gc.ca/NationalSecurity>

Soeters, J. L. 2005. Ethnic Conflict and Terrorism: The Origins and Dynamic of Civil Wars. New York: Routledge.

Stevens, T. and Neumann, P. R. 2009. Countering online radicalization: A Strategy for Action. International Centre for the Study of Radicalisation and Political Violence (ICSR) ICSR Publications, London.

Thompson, R. L. Radicalization and the use of Social Media. Journal of Strategic Security., 4 (4): 167-190.

Whitney, S. B. 2009. Mobilizing Youth: Communists and Catholics in Interwar France. Duke University Press: Durham and London. 